\title{
Clinical Trials in India: Missing the Finish Line
}

\author{
Vinay Mathew Thomas¹, Aju Mathew ${ }^{2,3}$ \\ ${ }^{1}$ Department of Internal Medicine, University of Connecticut Health \\ Center, Farmington, Connecticut, United States \\ 2University of Kentucky Markey Cancer Center, Lexington, \\ Kentucky, United States \\ ${ }^{3}$ Department of Oncology, MOSC Medical College Kolenchery, \\ Kochi, Kerala, India
}

Ind J Med Paediatr Oncol 2021;42:284-285.

Nonpublication of clinical trials leads to distortion of data available in medical literature. ${ }^{1}$ To address these issues, the US congress authorized the creation of a clinical trials registry, Clinicaltrials.gov, which would ensure that the public had access to information on clinical trials. ${ }^{1}$ Subsequently, the Clinical Trials Registry India (CTRI) was established in 2007. ${ }^{2}$ To decrease publication bias, the International Committee of Medical Journal Editors (ICMJE) made it mandatory for all clinical trials to be registered prospectively, for these trials to be considered for publication in member journals. ${ }^{3}$ The CTRI followed suit in April 2018 and made a similar requirement for trials conducted in India. ${ }^{2}$

Studies that have looked at the rates of publication in other registries such as Clinicaltrials.gov have found that the rates of nonpublication of results are significant, with some studies showing nonpublication rates as high as $54 \%{ }^{1}$ We recently published a research study that investigated publication rates of clinical trials in the CTRI. ${ }^{4}$ We identified cancer clinical trials registered in CTRI till February 2016. In doing so, we ensured that there was enough time for the trials to be published since the manuscript search started in December 2019. We identified 133 trials, which met our criteria of completed, interventional trials. We conducted a literature search to identify the publication rates of these trials. For a trial to be considered published, any data pertaining to the trial should have been published in a peer-reviewed journal.

Of the 133 studies, 73 (54.9\%) were published. We found that randomized controlled trials were more likely to be published than nonrandomized trials ( 61.4 vs. $34.4 \%, p=0.007$ ). We did not find any association between the type of sponsor (pharmaceutical vs. nonpharmaceutical) and the likelihood of publication ( 53.1 vs. $60 \%, p=0.479$ ). We also did not find a difference in the rates of publication in prospectively versus retrospectively registered studies ( 49 vs. $61 \%, p=0.14$ ).

DOI https://doi.org/ $10.1055 / \mathrm{s}-0041-1733829$ ISSN 0971-5851
Address for correspondence Aju Mathew, MBBS, MD, MPhil, FACP, AB (Med Onc, Hemat, Int Med), Department of Oncology MOSC Medical College Kolenchery, Medical College Road, PO Kolenchery, Kochi, Kerala 682311, India (e-mail: cancerkerala@gmail.com).

We did, however, find that trials were more likely to be published if they were sponsored by global pharmaceutical companies compared with Indian pharmaceutical companies ( 71.7 vs. $23.7 \%, p<0.00001$ ). Also, trials were more likely to be published if they were conducted at a multinational level compared with trials conducted in India alone (84 vs. $37.3 \%$, $p<0.00001$ ).

Our study shows that publication rates of completed clinical trials are suboptimal. Nonpublication of clinical trials can be detrimental to public health., ${ }^{5,6}$ There could be several reasons for the nonpublication of clinical trials. It is possible that trials with statistically nonsignificant or negative results are less likely to be published. Even though positive clinical trials indicate clinical advancement, it is important that negative trials be published, because it informs us which treatment options should not be used. ${ }^{7}$ Investigators may also choose not to publish if the results are different from what they anticipated. Protection of intellectual property could also be a consideration. ${ }^{1,8}$ Studies undertaken by international pharmaceutical companies and at a multinational level are more likely to be published. The reason for such a situation is unclear, although we can hypothesize that there is a higher standard for transparency and research integrity. There is also more assistance and mentoring in conducting and completing trials. The extremely low publication rates of trials conducted in India alone (37.3\%) should therefore be a cause for concern.

Nonpublication of results is a disservice to the participants of the studies. Participants often agree to participate in clinical not for the individual gains, but often for societal gains. Publication of research promotes transparency and ensures that all data are available to the public. The reason for low publication rates of clinical trials conducted in India is unclear. Could it be due to lack of motivation on the part of the researchers, or the lack of a proper research
(C) 2021. Indian Society of Medical and Paediatric Oncology.

This is an open access article published by Thieme under the terms of the Creative Commons Attribution-NonDerivative-NonCommercial-License, permitting copying and reproduction so long as the original work is given appropriate credit. Contents may not be used for commercial purposes, or adapted, remixed, transformed or built upon. (https://creativecommons.org/licenses/by-nc-nd/4.0/).

Thieme Medical and Scientific Publishers Private Ltd. A-12, Second Floor, Sector -2, NOIDA -201301, India 
infrastructure in India? Could it be possible that medical journals are biased against trials conducted by researchers in low- and middle-income countries like India?

In our analysis of the trials registered on the CTRI, we also found that many trials did not have their results entered on the website. However, the CTRI is working toward disclosure of results in a structured manner. ${ }^{2}$ We also found that $50.4 \%$ of trials were registered retrospectively. Retrospective registration of trials can introduce bias since favorable outcomes are more likely to be reported or published. ${ }^{9}$ Hopefully, the new CTRI mandate for compulsory prospective registration of trials will change that statistic for the better. Despite the push for more clinical research in India, we still have plenty of strides to make. Our findings should lead to introspection and action. We must push more cancer clinical trials in India to the finish line.

\section{Authors' Contribution}

Vinay Mathew Thomas and Aju Mathew were responsible for drafting, revision, and for final approval of the article for publication.

The manuscript has been read and approved by all the authors, the requirements for authorship as stated earlier in this document have been met, and each author believes that the manuscript represents honest work.

\section{Funding}

This research did not receive any specific grant from funding agencies in the public, commercial, or not-for-profit sectors.

\section{Conflict of Interests}

The authors declare that there is no conflict of interest.

\section{Acknowledgments}

None.

\section{References}

1 Jones CW, Handler L, Crowell KE, Keil LG, Weaver MA, Platts-Mills TF. Non-publication of large randomized clinical trials: cross sectional analysis. BMJ 2013;347:f6104

2 Vardhana Rao MV, Maulik M, Gupta J, et al. Clinical Trials Registry - India: an overview and new developments. Indian J Pharmacol 2018;50(4):208-211

3 Deangelis $C D$, Drazen JM, Frizelle FA, et al. International Committee of Medical Journal Editors. Clinical trial registration: a statement from the International Committee of Medical Journal Editors. Arch Dermatol 2005;141(1):76-77

4 Thomas VM, John VM, Alexander SA, Roy AM, Mathew A. Publication rate and characteristics of cancer clinical trials in India. Journal of Cancer Policy 2020;26:100248

5 Turner EH, Matthews AM, Linardatos E, Tell RA, Rosenthal R. Selective publication of antidepressant trials and its influence on apparent efficacy. N Engl J Med 2008;358(3):252-260

6 Nissen SE, Wolski K. Effect of rosiglitazone on the risk of myocardial infarction and death from cardiovascular causes. N Engl J Med 2007;356(24):2457-2471

7 Unger JM, Barlow WE, Ramsey SD, LeBlanc M, Blanke CD, Hershman DL. The scientific impact of positive and negative phase 3 cancer clinical trials. JAMA Oncol 2016;2(7):875-881

8 Blumenthal D, Campbell EG, Anderson MS, Causino N, Louis KS. Withholding research results in academic life science. Evidence from a national survey of faculty. JAMA 1997;277(15):1224-1228

9 Zarin DA, Tse T, Williams RJ, Rajakannan T. Update on trial registration 11 years after the ICMJE policy was established. N Engl J Med 2017;376(4):383-391 